\title{
SARS-CoV-2 and COVID-19 "covidiosyncrasies" and their impact on endoscopists and endoscopy
}

\author{
Referring to Belle A et al. p.1111-1115
}

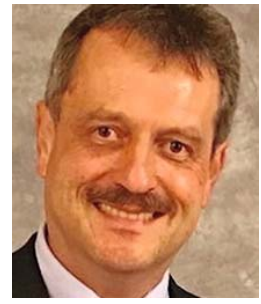

Klaus Mönkemüller

\author{
Author \\ Klaus Mönkemüller¹,2 \\ Institutions \\ 1 Department of Internal Medicine, Ameos Clinic, \\ Halberstadt and Teaching Hospital, Otto-von-Guericke \\ University, Magdeburg, Germany \\ 2 University of Belgrade, Belgrade, Serbia \\ Bibliography \\ Endoscopy 2020; 52: 1116-1117 \\ DOI 10.1055/a-1214-6252 \\ ISSN 0013-726X \\ (C) 2020. Thieme. All rights reserved. \\ Georg Thieme Verlag KG, Rüdigerstraße 14, \\ 70469 Stuttgart, Germany \\ Corresponding author \\ Klaus Mönkemüller, MD PhD, Dennig 18, \\ 96317 Kronach, Germany \\ moenkemueller@yahoo.com
}

The novel coronavirus SARS-CoV-2 and the systemic disease it causes, COVID-19, caught the World by surprise, as two of its predecessors SARS and MERS similarly did before, but this time this cantankerous virus entered center stage with a "wham." Half in weariness, half in trepidation, the World peered at this new virus that had combined two abilities: first, to infect humans through the nose and mouth, similarly to its ancestors the coronaviruses that cause the common cold and diarrhea; second, also keeping its invasiveness and causing severe lower respiratory tract disease, in the same vein as SARS and MERS [1].

Worse, owing to selection pressure, as occurs with all living microorganisms, SARS-CoV-2 had acquired a few additional sneaky tricks to avoid immunologic recognition, increasing its ability and avidity to invade human cells. First, SARS-CoV-2 does not travel with its crown spikes standing up, so it evades detection by the host. The virus is helped by human enzymes (serine proteases or furins) that activate the receptor binding domain, thereby helping to separate and raise these spikes [1]. Second, the novel configuration of the S-spike allows it to bind to the ACE2 receptors with a 10 - to 20 -fold increased strength $[1,2]$. And third, SARS-CoV-2 blunts essential parts of the human innate immune system by suppressing production of cellular interferon types I and III, so it can enter the cell inconspicuously [3]. A sneaky attack and subsequent hijacking of the human cell machinery to induce its own viral replication rapidly ensues. These new biological skills of the virus and the often na- ïve and complacent human behavior, summed up by the advantages of easy global travel conditions, allowed SARS-CoV-2 to spread abroad easily and rapidly, affecting all kinds of people, but also directly hitting patient-care providers.

"Although it is always good to reach for guidelines to assist in operational and patientcare decisions, the myriad of recommendations during the COVID-19 pandemic was very extensive, at times too exhaustive, and often confusing or contradictory."

In this issue of Endoscopy, we learn how the idiosyncrasies of COVID-19 plummeted endoscopy services and endoscopists into chaos and desperation. In the midst of the initial and precipitous wave of the COVID-19 pandemic, Belle et al. measured its impact on gastrointestinal (Gl) endoscopy activity in France [4]. The authors performed a web-based survey from 23 March to 27 March 2020, with a decent return of almost $700 \mathrm{Gl}$ endoscopists out of 3300 providing feedback. Almost all of the responders had had to cancel endoscopy activities. The chaos in the endoscopy departments was increased by removing the anesthesiologists usually dedicated to the endoscopy departments of $71.6 \%$ of the responders. Moreover, a third of those endoscopists also became involved in the management of COVID-19 patients outside the endoscopy department. Only a small 
minority of them (9.4\%) eventually performed urgent and emergent endoscopies on COVID-19 patients, with a median of 2.3 endoscopies during the week of the survey. A specific circuit for COVID-19 patients had been organized for only $44 \%$ of the endoscopy departments. Of concern, $56.8 \%$ of the responders performed procedures without wearing a mask. Furthermore, the practitioners reported difficulty obtaining the entire range of personal protection equipment (PPE): masks, eye protection, gowns, gloves, surgical caps, and hydroalcoholic gel. Worryingly, $12.8 \%$ of the gastroenterologists reported having symptoms compatible with COVID-19 infection [4].

This study stands out for providing a snapshot of the disruptive effect that the COVID-19 pandemic had on the workflow and safety of Gl endoscopy units and endoscopists. The ominous findings of this study reflect the experiences elsewhere [5-7]. As shown in similar studies from Italy and Brazil, endoscopists struggled massively with uncertainties and the resulting shortages of personnel and PPE [4, 5]. Furthermore, the COVID19 pandemic has also negatively impacted the training of future gastroenterologists worldwide [7]. Whereas in France there was an initial total shutdown for almost all endoscopy procedures, in Brazil and Italy some endoscopists continued to perform elective procedures $[5,6]$. Continuing to perform elective procedures is not unreasonable and will certainly depend on the region where the endoscopist practices. It is crucial to note that the distribution of COVID-19 and its Rt vary tremendously among regions and creating a uniform response to the pandemic threat would have a negative impact on patient care, as limiting procedures to only urgent and emergent cases would certainly lead to delays in care for many subacute or worsening chronic gastroenterological conditions.

Suddenly, a plethora of recommendations were poured into the literature. Although it is always good to reach for guidelines to assist in operational and patient-care decisions, the myriad of recommendations was very extensive, at times too exhaustive, and often confusing or contradictory [8]. To add to the stress of endoscopists, some guidelines recommended constructing new rooms with laminar flow to perform endoscopy. It was also not clear whether cold or hot water should be used when washing hands. Some guidelines recommended that, if a patient with confirmed COVID-19 had undergone an endoscopy, the team should take a shower after the procedure. Currently, there are not enough shower rooms and toilets in most endoscopy units in the World. Suddenly, applying alcohol gel on top of gloves before removing them became "standard." The dangers of permeability-induced changes to nitrile gloves with disinfectants, as well as the scarcity of gel disinfectant, as evidenced by reports from all over the World, made this recommendation ad absurdum. Some have recommended using head and shoe covers, others have recommended changing all clothes after each endoscopy. At one point, I started to believe that the hygiene standards and rules were being re-invented by the new guidelines, and it appeared as if endoscopists had only just discovered the benefit of using goggles and a gown to perform endoscopy. Disinfection of scopes was also questioned, with some guidelines recommending running the scopes twice through the washing and disinfection process.
My two pieces of advice when dealing with such a panoply of recommendations are: (a) to go back to basics, such as understanding the pathophysiology of the disease, its clinical manifestations and its epidemiology; and (b) to establish local and regional response guidelines.

Belle et al. also report on the occurrence of COVID-19 symptoms or infections in a significant number of endoscopists. A deficit of their study was the inability to confirm these infections objectively. Nevertheless, it is clear that many physicians and nurses around the World dealing with COVID-19 patients have become infected or died. Whether the infection occurred during endoscopy procedures is still unclear; however, many gastroenterologists had to "change hats" and cover emergency rooms, wards, and intensive care units to treat COVID-19 patients. Indeed, in many countries, some hospitals converted to "only COVID-19" for a period of several months. Of course, frequent exposure to SARS-CoV-2 increases the chances of infection. Nevertheless, we suspect that many of these infections and deaths were likely due to the unavailability of proper PPE.

In summary, COVID-19 has significantly impacted the way we practice endoscopy, affecting patients and medical staff alike. Notwithstanding the fastidious and tedious road to normality, the stepwise resumption of elective endoscopy work will be strengthened by newly acquired and funded knowledge on the viral characteristics and an understanding of the idiosyncrasies of SARS-CoV-2.

\section{Competing interests}

The author declares that he has no conflict of interest.

\section{References}

[1] Mönkemüller K, Fry L, Rickes S. COVID-19, coronavirus, SARS-CoV-2 and the small bowel. Rev Esp Enferm Dig 2020; 112: 383-388

[2] Wrapp D, Wang N, Corbett KS et al. Cryo-EM structure of the 2019nCoV spike in the prefusion conformation. Science 2020; 367: 12601263

[3] Blanco-Melo D, Nilsson-Payant BE, Liu WC et al. Imbalanced host response to SARS-CoV-2 drives development of COVID-19. Cell 2020; 181: 1036-1045.e9

[4] Belle A, Barret M, Bernardini D et al. Impact of the COVID-19 pandemic on gastrointestinal endoscopy activity in France. Endoscopy 2020: 1111-1115

[5] Arantes VN, Martins BC, Seqatto R et al. Impact of coronavirus pandemic crisis in endoscopic clinical practice: Results from a national survey in Brazil. Endosc Int Open 2020; 8: E822-E829

[6] Maida M, Sferrazza S, Savarino E et al. "Impact of the COVID-19 pandemic on Gastroenterology Divisions in Italy: a national survey". Dig Liver Dis 2020: doi:10.1016/j.dld.2020.05.017

[7] Pawlak KM, Kral J, Khan R et al. Impact of COVID-19 on endoscopy trainees: an international survey. Gastrointest Endosc 2020: doi:10.1016/j.gie.2020.06.010

[8] Castro Filho EC, Castro R, Fernandes FF et al. Gastrointestinal endoscopy during the COVID-19 pandemic: an updated review of guidelines and statements from international and national societies. Gastrointest Endosc 2020: doi:10.1016/j.gie.2020.03.3854 